Communication, technologies et développement

\section{3| 2016}

Le développement au risque de l'information

\title{
Pensando caminhos alternativos : a perspectiva do jornalismo cívico
}

Réflexion sur des voies alternatives : la perspective du journalisme civique

Thinking alternative paths: the perspective of civic journalism

Fernanda Vasques Ferreira e Marcelli Alves

\section{OpenEdition}

Edição electrónica

URL: http://journals.openedition.org/ctd/1052

DOI: $10.4000 /$ ctd. 1052

ISSN: 2491-1437

Editora

Chaire Unesco Pratiques émergentes en technologies et communication pour le développement

Edição impressa

Data de publição: 30 outubro 2016

ISBN: 2491-1437

\section{Refêrencia eletrónica}

Fernanda Vasques Ferreira et Marcelli Alves, «Pensando caminhos alternativos : a perspectiva do jornalismo cívico », Communication, technologies et développement [En ligne], 3 | 2016, mis en ligne le 21 février 2019, consulté le 12 juin 2020. URL : http://journals.openedition.org/ctd/1052 ; DOI : https:// doi.org/10.4000/ctd.1052

Este documento foi criado de forma automática no dia 12 junho 2020

Communication, technologies et développement 


\title{
Pensando caminhos alternativos : a perspectiva do jornalismo cívico
}

\author{
Réflexion sur des voies alternatives : la perspective du journalisme civique \\ Thinking alternative paths : the perspective of civic journalism
}

Fernanda Vasques Ferreira e Marcelli Alves

1 A intenção deste trabalho é discutir as nomenclaturas destinadas ao jornalismo que tem como sua base a participação do público. Discutiremos os termos jornalismo cívico e jornalismo público seguindo a linha dos autores lusófonos Traquina (2002) e Canavilhas (2011) e do brasileiro Rothberg (2011).

2 Para Traquina (2002), jornalismo cívico é uma brecha ao jornalismo convencionale, para conseguir espaço, esse novo jornalismo não representa o fim do jornalismo existente, mas sim uma renovação daquilo que a sociedade já conhece.

Para o jornalismo cívico, torna-se um imperativo que o jornalismo encoraje o envolvimento do cidadão na vida pública, desenvolvendo nos jornalistas uma nova perspectiva - a perspectiva do "participante justo" - com a utilização de um novo instrumento de trabalho. (TRAQUINA, 2002, p. 13)

3 Em sua obra Traquina (2002) discute o conceito de jornalismo cívico antes explorado por Merrit. De acordo com o autor, trata-se de um movimento que surgiu na década de 1980 nos Estados Unidos da América e apresentava um novo modelo para o jornalismo da época. Traquina (2002) define esse movimento como um dos mais importantes dos últimos anos em se tratando de discussão comunicativa, pois tinha como proposta a reavaliação daquilo que até então era considerado como base para o jornalista.

O movimento que embasou o jornalismo cívico provocou uma discussão intensa no jornalismo norte-americano no que tange os valores fundamentais da profissão. Para Traquina (2002) o jornalismo cívico tem o potencial para renovar o jornalismo se não pretender ser uma ruptura com o seu capital já acumulado. Dessa forma, essa nomenclatura é específica para demonstrar a relação entre o cidadão e a esfera pública.

Sabemos que essa participação não é nova, visto que o movimento no qual o autor considera foi realizado entre os anos 30 e 40 . No entanto, atualmente a maneira como 
ela ocorre foi enaltecida pelas novas tecnologias e isso impactou de forma direta a comunicação e tem gerado outras terminologias além da discutida por Traquina (2002). Além disso, inspiraram programas de treinamento em todo o mundo dedicados a ensinar o jornalismo em um ambiente no qual a participação é cada vez mais presente. "The literature on the impact of converging technologies on the practice and education of journalists is expanding rapidly. Digital media and, more recently, multimedia newsrooms are transforming training and education of journalism worldwide" (CASTANEDA, 2003, Apud DEUZE, 2005, p. 449).

6 Castells (2007) afirma que o mundo passou por uma revolução tecnológica e de alguma forma toda a sociedade é atingida por esse processo. Segundo o autor, a tecnologia não determina a sociedade, e sim a incorpora. Já a sociedade não determina a inovação tecnológica, e sim a utiliza. É da mesma fonte a informação que essas novas tecnologias representam uma nova mídia e acabam por determinar um novo modelo comunicacional regido, principalmente, por um novo ingrediente no qual ele diz que é a audiência que tende a escolher as suas mensagens.

7 Várias termologias surgiram, sobretudo, na última década, na tentativa de referendar a relação direta do público em diferentes etapas do processo da construção da notícia e tem influenciado para um novo momento na comunicação, principalmente, no jornalismo. Além dos termos cívico e público que é o foco de nossa discussão, apresentaremos de forma sucinta terminologias trazidas para a comunicação no que tange à participação do público. Achamos plausível citarmos a definição de Andreson (2006), Brambilla (2005), Gillmor (2004) e nos aprofundaremos mais em Traquina (2002) e Rothberg (2011), que são, respectivamente : cauda longa ou jornalismo de código aberto, jornalismo open source, jornalismo colaborativo, participativo e/ ou cidadão e jornalismo cívico ou público. É válido lembrar que sobre este último destacaremos a experiência explorada por Canavilhas (2011) no que tange ao ambiente virtual.

8 No entanto, o que é preciso lembrar é que embora pareçam sinônimos, as referidas terminologias nem sempre o são. Isso se aplica no caso do termo open source que migrou do meio da engenharia de software para o jornalismo, como uma forma de explicar uma produção de notícia relacionada às novas tecnologias. "Se as notícias, assim como os softwares, eram exclusivamente produzidas e publicadas por uma empresa que as transforma em produtos comercializáveis, no jornalismo open source elas passam a ser produto de domínio público, tanto sua elaboração quanto sua fruição" (BRAMBILLA, 2005, p. 10).

9 Foschini e Taddei atribuem ao jornalismo open source "um estilo de jornalismo feito em sites wiki, que permitem a qualquer internauta alterar o conteúdo de uma página" (2006, p. 19). Ambos definem os sites wiki como os meios livres no qual todos podem editar. Ou seja, o jornalismo open source está mais voltado à participação ativa do internauta em interação mútua com o conteúdo noticioso.

Diferente do termo 'Cauda Longa', cunhado por Anderson (2006). Essa terminologia está relacionada à maneira como as tecnologias estão convertendo o mercado de massa em milhões de nichos. Para exemplificar o que quer dizer, o autor conta em sua obra, história que ocorreu no ano de 1988, na qual um montanhista inglês, chamado Joe Simpson, escreveu um livro intitulado "Tocando o vazio". No livro, ele relatava a sua sobrevivência nos Andes peruanos, depois de um acidente. Anderson (2006) explica que apesar das resenhas favoráveis, o livro fez pouco sucesso, foi vendido de forma tímida e logo caiu no ostracismo. No entanto, anos depois, um outro livro, porém do autor Jon 
Krakauer, chamado "No ar rarefeito" que também tratava sobre tragédia relacionada ao montanhismo, tornou-se sensação no mundo editorial. E, em pouco tempo, o livro "Tocando o vazio", que, anteriormente havia caído no esquecimento, começou a vender novamente. E vendeu muito, superando todas as expectativas. A justificativa que o autor dá para esse fato é que foi feito, o que ele chama de divulgação 'boca a boca' online. Ele complementa a explicação dizendo que na ocasião do lançamento do livro "No ar rarefeito", alguns leitores enviaram resenhas para o site amazon.com (empresa multinacional de comércio eletrônico) apontando as semelhanças com o então livro "Tocando o vazio" e o cobriam de elogios. Outros compradores leram essas resenhas e acabavam por comprar a obra, também, deflagrando o que ele chama de loop de feedback positivo.

11 Sobre este fato, Anderson (2006) esclarece que os dados sobre vendas e as tendências desses serviços e de outros semelhantes revelam que a economia emergente do entretenimento digital é diferente do entretenimento de massa, dando vistas à colaboração. $O$ autor cita situações para exemplificar o termo The Long Tail (Cauda Longa) pois ele retirou a terminologia, comum em textos estatísticos, para aplicá-la em outras áreas. O seu primeiro uso estava relacionado a economia em abundância. "O que acontece quando os gargalos que se interpõem entre a oferta e a demanda em nossa cultura começam a desaparecer e tudo se torna disponível para todos" (Anderson, 2006, p. 11).

$12 \mathrm{O}$ autor enfatiza que a internet transformou os cidadãos em distribuidores de conteúdos e alerta sobre o impacto dessa produção em abundância sobre outra perspectiva, que segundo ele, impactou, inclusive, na redução significativa da produção de jornal, se comparado com a década de 80. "Esse fato é a prova concreta do efeito revolucionário que a cauda longa é capaz de exercer sobre as indústrias tradicionais" (Anderson, 2006, pág. 64). o exemplo de Anderson (2006) é trazido para o cenário jornalístico e, segundo ele, essa realidade privilegia a difusão de notícias encaminhadas pelo público, gerando uma inquietação a respeito do sistema jornalísticos tradicionais.

13 Seguindo a linha de pensamento, Gillmor (2004) traz à tona os termos jornalismo participativo e/ou cidadão, que para ele são sinônimos da ideia de intercâmbio entre quem produz a notícia (jornalista) e quem consome (espectador) e complementa "The tools of tomorrow's participatory journalism are evolving quickly-so quickly that by the time this book is in print, new ones will have arrived." (Gillmor, 2004, p. 25). Para exemplificar, o autor diz que nos últimos cento e cinquenta anos a humanidade tinha apenas dois meios distintos de comunicação que ele chama de um para muitos e de um para um. 0 um para muitos, segundo ele, seriam os livros, jornais, rádio e a TV e o um para um seriam as cartas, telégrafos e telefones. $O$ autor acredita que a mudança nesse cenário significa um grande impacto na comunicação, e, consequentemente, na vida das pessoas.

14 Partindo dessas premissas, mais uma vez recorremos a Traquina (2002, p 178). Para ele, o jornalismo cívico envolve as seguintes mudanças no modelo convencional de comunicação :

15 Ir para além da missão de dar as notícias para a missão mais ampla de ajudar a vida pública.

16 Deixar para trás a noção do "observador desprendido" e assumir o papel de "participante justo". 


\section{responder aos desafios diários e, ainda mais, assumir também os custos de ser o campeão de uma vida púbica vibrante?}

responsabilidades ao velho jornalismo e pergunta onde estão os recursos para

21 Martins da Silva (2013) propõe uma análise do jornalismo e sua função social a partir de uma aproximação com o mundo do trabalho. Ele desenvolve análise importante ao avaliar que o jornalismo tem especificidades e não é como uma profissão qualquer. 0 pós-jornalismo envolve se não esforços, pelo menos, trabalho extra para os membros da comunidade jornalística. Martins da Silva (2013) cunha o termo sobretrabalho. Ao dividir o jornalismo em três categorias : o protojornalismo, o jornalismo e o pósjornalismo, o autor parte da premissa de que, na nova era, a do pós-jornalismo, o jornalista transforma a informação num produto social com valor de troca característico. Isso se deve ao fato de que a contemporaneidade faz novas exigências do jornalismo e, para cumpri-las, os jornalistas passam a ter uma jornada de trabalho adicional - o sobretrabalho

- inerente, segundo Martins da Silva (2013) à função social da profissão.

23 Ao observar a cobertura da violência nas escolas, por exemplo, Martins da Silva (2013) explica que o fenômeno pode receber tratamento de impacto e, portanto, constituir-se com um sentido sensacionalista - o autor associa essa cobertura à imprensa de centavos ou penny press, mas também poderá ser noticiado e bem contextualizado - como os jornais de referência. Outra abordagem epistemológica do acontecimento midiático pode ser ao que o autor denomina como "campanha jornalística", composta por uma série de matérias ou cobertura especial voltada para o tema, traduzindo o problema e indicando possíveis soluções. Dessa maneira, o jornalismo contribuiria para que a violência nas escolas deixasse de ser um fato jornalístico isolado passando a ser um tema de mobilização social.

Nesse caso, os impactos esperados vão muito mais além dos aspectos dramáticos explorados pelo "jornalismo popular", com também ultrapassam a efemeridade que usualmente caracterizam a sucessão de fatos, em que, por exemplo, uma onda de acidentes de trânsito venha subsumir as notícias e reportagens sobre violência nas escolas. 
Um dos problemas do jornalismo de 'informação' é o envelhecimento precoce dos temas, dada o seu rápido esgotamento enquanto fato 'novo'. Na realidade, novo apenas como circunstância, ou, como "gancho", como se diz na gíria das redações. No presente, e, portanto, da vigência do paradigma do jornalismo de "comunicação", dificilmente uma enxurrada de episódios de agressão entre jovens escolares será 'coberta' apenas no caso a caso. 0 mais esperado é que o veículo de comunicação, face ao seu vínculo social (para com o cidadão e com a cidadania), assuma uma vita activa (Hannah Arendt) perante tal contexto de violência, atuando como 'parceiro' social na busca de um novo patamar de cultura de paz, ou até mesmo assuma a liderança da mobilização, como o fez o Correio Braziliense, quando da 'campanha do trânsito` em Brasília, que resultou na institucionalização da faixa de pedestres em todo o Distrito Federal e na difusão de uma série de condutas de Paz no Trânsito, como o "sinal de vida", hoje assimilado, reconhecido e respeitado por todos (a não ser por eventuais e isoladas transgressões). (Martins Da Silva, 2013, p. 15)

24 Correia (2009) explica que o jornalismo cívico trata da identificação e promoção de práticas jornalísticas que contribuam para reforçar o compromisso dos cidadãos com a comunidade. Essa abordagem, segundo o autor, se centra nas articulações entre "jornalismo público" e jornalismo regional. O autor esclarece que a campanha presidencial norte-americana de 1988 foi um evento que desencadeou o aparecimento do jornalismo público. Naquele contexto, observou-se que os meios de comunicação deram espaço para questões secundárias, enfatizando na cobertura jornalística, aspectos relacionados com a vida pessoal dos candidatos, com intrigas políticas e, portanto, deixando de noticiar questões de interesse público. Essa situação apenas realçou a crise de credibilidade dos media e dos profissionais - os jornalistas, resultando num declínio de tiragens e audiências.

Segundo Correia (2009), é neste contexto que surgem as primeiras experiências de jornalismo público, que emergem assim associadas a uma tentativa de repensar o paradigma jornalístico. O movimento considerou que era preciso reanimar a vida pública e que o jornalismo deveria desempenhar um papel nesse processo (Merritt, 1998, p. 11 Apud Correia, 2009, p. 09).

o jornalismo cívico tratado por Traquina (2002) também tem sua nomenclatura estendida para jornalismo público. O também português João Canavilhas (2011) explora o assunto e enumera as características atribuídas a esse tipo de comunicação.

Entre as suas principais características encontram-se : a) a necessidade de ouvir sistematicamente as histórias e ideias dos cidadãos ; b) a importância de examinar formas alternativas de se aproximar dessas histórias a partir de pontos de vista considerados importantes pela comunidade ; c) a escolha de abordagens em que a apresentação das questões oferece maior oportunidade para estimular a deliberação dos cidadãos ;

d) proporcionar a informação de modo a aumentar o conhecimento público sobre as possíveis soluções e os valores envolvidos nas opções alternativas; e e) atenção sistemática à qualidade da comunicação no relacionamento com o público. (CANAVILHAS, 2011, p. 60).

$\mathrm{O}$ autor enfatiza que o elemento de controvérsia mais forte da história do jornalismo cívico diz respeito às normas de autonomia e objetividade. Item também questionado por Traquina (2002). Canavilhas diz que o jornalismo público busca interpelar o cidadão para que ele participe, fazendo com que a imprensa seja mais que mediadora, mas um espaço de mediação ajudando na construção da cidadania. Já Canavilhas (2011) vai além 
e busca nas premissas do filósofo alemão a definição a questão da objetividade relacionada ao "terceiro setor".

o núcleo central da Sociedade Civil será, consequentemente, uma"rede de associações que institucionalizam a solução discursiva de problemas sobre questões de interesse geral dentro do quadro de esferas públicas organizadas" (Habermas, 1996, p. 367 apud Canavilhas, 2011, p. 61)

Canavilhas (2011) discute a terminologia jornalismo público aplicada a um estudo empírico afim de entender quando e por qualmotivo surgem interesses e qualé o papel do jornalismo na superação das negociações que ocorrem ao nível pré-político nas redes sociais. Para isso, ele explora o projeto chamado "agenda cidadã : o jornalismo e participação cívica nos media portugueses". Este projeto surgiu com o objetivo de identificar e testar práticas jornalísticas que contribuam para reforçar o compromisso dos cidadãos com a comunidade e a deliberação democrática na esfera pública regional, incluindo nove jornais portugueses: Grande Porto, Jornal da Bairrada, Jornal do Centro, Diário As Beiras, Ribatejo, Vidas Ribatejanas, Região de Leiria, Jornal do Fundão e O Algarve. 0 objetivo foi criar uma agenda ditada pelos problemas, preocupações e questões avaliadas como relevantes por parte dos cidadãos, criando o que pode ser chamado de "agenda do cidadão".

$\mathrm{O}$ autor conclui que as abordagens apenas empíricas ignoram a relação com a vida pública e reduzem o jornalismo a um conjunto de práticas que estão entrelaçadas à necessidade de produção de uma mercadoria rentável. Pensamento similiar a McManus, (1994, apud Traquina 2002), no qual ele enfatiza que o jornalismo cívico representa uma busca constante pela notícia, visando uma questão mercantilista, deixando o jornalismo numa dependência excessiva das fontes oficiais.

Ainda sobre a perspectiva de escritores lusófonos, temos o brasileiro, professor do departamento de Ciências Humanas da Universidade Estadual de São Paulo, Unesp, Danilo Rothberg. $O$ autor explora o tema sobre perspectivas diversas além de explicar sobre sua pesquisa empírica que desenvolveu na Inglaterra no período de seu pósdoutorado.

Para Rothberg (2011), o acesso à informação é um direito fundamental de todo cidadão que vive em uma sociedade democrática. Ele elege o jornalismo público como o principal responsável pelo incentivo da participação popular nas questões que envolvem a todos. Assim como Traquina (2002), e Canavilhas (2011), o autor também trata das questões da objetividade no jornalismo.

Para ele, a objetividade deve se distanciar do conceito de neutralidade. "A inviabilidade de eliminar das reportagens as visões dos jornalistas e outras perspectivas particulares que contaminam os julgamentos dos profissionais da área, mesmo sem eles se darem conta delas" (Rothberg, 2011, p. 86).

\section{Conclusão}

Diante de nossa pergunta inicial, identificamos que há diferentes nomenclaturas que abrangem o jornalismo cunhadas por autores lusófanos e brasileiros. A discussão sobre os valores fundamentais da profissão gerou, desde os anos 80 até os dias atuais, intensos debates acadêmicos que receberam relevo após o surgimento das tecnologias que intensificaram ainda mais os processos comunicacionais. É certo que os diferentes prismas apresentados pelos autores nos dão condições de refletir e sinalizam 
possibilidades e alternativas para que o jornalismo - enquanto uma atividade profissional que se enquadra em padrões e processos e que tem um papel legitimado na sociedade com função social definida e reconhecida pelos cidadãos - possa se consolidar como uma atividade reconhecidamente atrelada aos ideais de cidadania, sem com isso deixar de ser uma atividade mercadológica. Se parte do trabalho do jornalista é estar em busca do que é extraordinário, a profissão não se estabelece somente com o valor de troca, mas também com o valor de uso, conforme nos esclarece Martins da Silva (2013, p. 14) "Mas nem só de singularidades vive a notícia e o noticiador. E, ao final de sua jornada, descobre o jornalista que para além do jornalismo-espetáculo ele tem igualmente de produzir algo de útil e de prestação de serviço".

Portanto, entre os diferentes tensionamentos existentes na profissão, um deles sobressai, para além do já tão desgastado e questionável discurso da objetividade : o de agregar valor de uso às informações para cidadãos, consumidores, comunidade, sociedade, para que a democracia e uma ética planetária possam se consolidar. Martins da Silva (2013) defende a ideia de que o jornalista exerce papel cotidiano de "rolar pedra montanha acima" e atrelado a isso tem de buscar algo que seja interessante e importante do ponto de vista do cidadão. É sobre esse dever cívico do jornalismo que este artigo se debruçou e tentou esclarecer como o que se apresenta como um ideal para muitos um ideal abstrato e intangível - pode se apresentar como uma solução para as crises e enfrentamentos do jornalismo enquanto atividade institucional e legitimada pela sociedade.

\section{BIBLIOGRAFIA}

Brambilla, A.M. Jornalismo open source em busca de credibilidade. In Intercom 2005

XXVIII. Congresso brasileiro interdisciplinar de ciências da

Comunicação, 09, 2005, Rio de Janeiro. Anais. Rio de Janeiro, 2005.

Canavilhas, J. Correia, J. C. ; carvalheiro, J. R. ; Morais, R. ; Sousa, J. C.

Jornalismo Público e Educação para os Media : sugestões baseadas num projeto de pesquisa sobre Imprensa Regional Portuguesa. Brazilian Journalism Research (Online), v. 7, p. 58-74, 2011.

Castells, Manuel. O Poder da Identidade. São Paulo : Paz e Terra, 2006. in Aeradainformação :

Economia, sociedade e cultura. 2007.

Correia, João Carlos (coord.). Agenda dos Cidadãos : jornalismo e participação cívica nos media portugueses memória de um projecto. Covilhã, LabCom Books : 2014.

Deuze, M. Wat is journalistiek? [What is journalism ?] Amsterdam : Spinhuis. 2005. GILLMOR, Dan. We, the media. Lisboa : Editorial Presence, 2004.

Martins Da Silva, L. Jornalismo e pós-jornalismo, trabalho e sobretrabalho. Esferas, Brasíla, número 2, 11-17, 2013. 
Rothberg, D. Jornalismo público : informação, cidadania e televisão. São Paulo, Unesp, 2011. Traquina, N. Jornalismo Cívico. Lisboa : Livros Horizonte, 2003.

\section{RESUMOS}

Diante das crises pelas quais passam os jornais no mundo inteiro, estaria o jornalismo fadado ao fracasso? Que alternativas poderiam alterar o contexto em que se inserem os jornais e jornalistas? Foi a partir desse questionamento que iniciamos uma revisão bibliográfica de autores lusófonos e brasileiros que discutem o que poderia ser um caminho - não necessariamente novo, mas contraditoriamente inovador - para "salvar" o jornalismo: o jornalismo cívico. $O$ termo não é consenso entre autores, mas entre eles, há um traço em comum : o fato de que o jornalismo precisa se aproximar dos cidadãos. 0 método utilizado para a produção desse trabalho é a revisão bibliográfica que nos orienta do ponto de vista teórico e metodológico.

Face aux crises que connaissent les journaux du monde entier, le journalisme est-il condamné à l'échec ? Quelles alternatives pourraient changer le contexte dans lequel évoluent les journaux et opèrent les journalistes? C'est cette question qui a orienté la revue de la littérature lusophones et brésiliens portant notamment sur ce qui pourrait être un moyen pas nécessairement nouveau, mais innovant - permettant de "sauver" : le journalisme « civique ». Il n'y a pas de consensus sur ce terme mais la plupart des auteurs conviennent que le journalisme doit être plus proche des citoyens. La revue de la littérature a donc orienté ce travail aussi bien sur le plan méthodologique que théorique.

Deal with crises in international journals, it is journalism comdamné to the failure? condemned? What could change the contaxte in which journalists operate? It was from this question that started a literature review of Lusophone authors and Brazilians discuss what could be one way - not necessarily new, but contradictorily innovative to «save " journalism : civic journalism. The term is no consensus among authors, but among them, there's a trait in common: the fact that journalism needs to be closer to citizens. The method used for the production of this work is the literature review that guides us from the theoretical and methodological point of view.

\section{ÍNDICE}

Mots-clés: journalisme civique ; journalisme public ; participation ; public ; citoyenneté

Keywords: civic journalism ; public journalism ; participation ; public ; citizenship

Palavras-chave: jornalismo cívico ; jornalismo público ; participação ; público ; cidadania.

\section{AUTORES}

\section{FERNANDA VASQUES FERREIRA}

Universidade de Brasília

\section{MARCELLI ALVES}

Universidade de Brasília 